sexual healthcare. Incapacitation cannot justify criminalisation in this case.

Conclusion Prosecution for non-intentional transmission of HIV through consensual sexual intercourse satisfies few of the justifications for punishment. The case for criminal sanctions should be reconsidered.

\section{P179 LIFE-TIME AND RECENT RECREATIONAL DRUG USE IS MORE COMMON AMONG MEN WHO HAVE SEX WITH MEN COMPARED TO OTHERS ATTENDING SEXUAL HEALTH CLINICS}

doi:10.1136/sextrans-2012-050601c.179

P I Dargan, L Hunter, J A White, ${ }^{*}$ A Benzie, D M Wood. Clinical Toxicology, Emergency Department and Sexual Health, Guy's and St Thomas' NHS Foundation Trust and King's Health Part, London, UK

Background Data on the frequency of recreational drug use (RDU) are collected at a population level through representative national surveys (eg, British Crime Survey). Anecdotally it appears that RDU is more common in men who have sex with men (MSM), but there are few systematic data to prove this. The aim of this study was to investigate the pattern of RDU in patients attending a sexual health clinic and to determine whether drug use was greater among MSM. Methods We administered a questionnaire to all patients attending the sexual health clinics at two inner-city London teaching hospitals over a 3-month period (July 2011-September 2011). The questionnaire was self-completed by patients while waiting to see a clinician. Data were collected on age, gender, gender of sexual partner(s) and previous/current RDU (type and frequency of drugs used).

Results 1328 questionnaires were completed (mean \pm SD age $30.5 \pm 8.5$ years, $54.9 \%$ female); 254 (19.1\%) were MSM. Life-time use of all drugs, except cannabis, was more common in MSM; lastmonth use of all drugs, except cannabis, cocaine powder and amphetamine, was more common in MSM (abstract P179 table 1).

Abstract P179 Table 1 Frequency of lifetime and last month use among the men who have sex with men (MSM) and non-MSM respondents

\begin{tabular}{|c|c|c|c|c|c|c|}
\hline & \multicolumn{3}{|c|}{ Lifetime use } & \multicolumn{3}{|c|}{ Last-month use } \\
\hline & MSM (\%) & $\begin{array}{l}\text { Non- } \\
\text { MSM (\%) }\end{array}$ & p Value & MSM (\%) & $\begin{array}{l}\text { Non- } \\
\text { MSM (\%) }\end{array}$ & p Value \\
\hline Cannabis & 62.7 & 58.4 & 0.23 & 10.2 & 9.2 & 0.62 \\
\hline Cocaine (powder) & 48.6 & 32.8 & $<0.001$ & 4.3 & 2.6 & 0.14 \\
\hline MDMA (pill) & 40.8 & 30.8 & 0.002 & 2.7 & 0.9 & 0.02 \\
\hline Mephedrone & 23.9 & 12.2 & $<0.001$ & 3.1 & 0.1 & $<0.001$ \\
\hline Ketamine & 33.7 & 17.3 & $<0.001$ & 3.5 & 0.5 & $<0.001$ \\
\hline Volatile nitrites & 71.4 & 26.9 & $<0.001$ & 18.4 & 0.4 & $<0.001$ \\
\hline Sildenafil (Viagra) & 43.5 & 15.7 & $<0.001$ & 11.8 & 0.5 & $<0.001$ \\
\hline Amphetamine & 29.8 & 21.2 & 0.003 & 0.8 & 0.3 & 0.23 \\
\hline $\begin{array}{l}\text { Gamma-hydroxybutyrate } \\
\text { (GHB) }\end{array}$ & 22.7 & 11.1 & $<0.001$ & 2.4 & 0.1 & $<0.001$ \\
\hline $\begin{array}{l}\text { Gamma-butyrolactone } \\
\text { (GBL) }\end{array}$ & 16.1 & 8.8 & $<0.001$ & 3.1 & 0.1 & $<0.001$ \\
\hline Methamphetamine & 16.9 & 9.0 & $<0.001$ & 1.2 & 0.2 & 0.02 \\
\hline
\end{tabular}

Conclusion Sexual health clinics provide an ideal forum to identify individuals using recreational drugs and to implement behavioural interventions and education programmes to promote safer RDU, reduce drug-related harm and, in view of the association between RDU and high risk sexual behaviours, to decrease the risk of subsequent STIs. Our data show that both life-time and last-month use of most recreational drugs are more common in MSM and therefore interventions should be targeted to this population.

\section{P180 \\ VULVAL PATHOLOGY IN HIV POSITIVE WOMEN ATTENDING A TERTIARY VULVAL DERMATOLOGY CLINIC OVER A 5-YEAR PERIOD}

doi:10.1136/sextrans-2012-050601c.180

0 Dosekun, ${ }^{*}$ P Farrugia, F Lewis, G Sethi. Guy's and St. Thomas' NHS Foundation Trust, London, UK

Background Studies have suggested that HIV infected women are at increased risk of developing invasive vulval carcinoma and recurrent herpes simplex type 2 (HSV-2) reactivation.

Objective To describe the spectrum of HIV associated vulval disease in women attending a tertiary dermatology referral centre in a busy urban setting.

Methods A retrospective case note review of all HIV positive women seen in the vulval dermatology clinic from January 2007 to January 2012.

Results 11 women were identified (see abstract P180 table 1). 9 (81\%) were black Africans. The mean age at vulval disease diagnosis was 37 years. Most (81\%) were already known to be HIV infected and on combined antiretroviral therapy (cART). There were six cases of undifferentiated vulval intra-epithelial neoplasia (uVIN) (43\%) with two cases being diagnosed prior to an HIV diagnosis The three cases of HSV-2 occurred in women with near-complete immune restoration on cART. Six women remain under regular dermatology follow-up, a median of 20 months since diagnosis.

Abstract P180 Table 1 HIV positive women seen in vulval dermatology clinic 2007 to 2012

\begin{tabular}{lllll}
\hline Case & Vulval diagnosis & On cART* & CD4 (cells/ $\mu$ I)* & VL (copies/ml) \\
\hline 1 & Multifocal uVIN & NA & NA & NA \\
2 & Multifocal uVIN & Yes & 761 & 235 \\
3 & Multifocal uVIN & Yes & 479 & 97 \\
& HSV-2 & Yes & 351 & 20 \\
4 & Lichen simplex chronicus & Yes & 502 & 366 \\
& Condyloma & Yes & 975 & 20 \\
5 & uVIN & NA & NA & NA \\
& Vulval lichen simplex & NA & NA & NA \\
6 & SCC in situ outer aspect & Yes & 268 & 40 \\
& labium majus & & & \\
7 & uVIN & Yes & 318 & 71 \\
8 & Chronic hypertrophic HSV-2 & Yes & 590 & 40 \\
9 & Multifocal uVIN of & Yes & 826 & 88 \\
& Bowenoid type & & & 63 \\
10 & Recurrent HSV-2 & Yes & 784 & 30441 \\
11 & Eczema & Yes & 62 & \\
\hline
\end{tabular}

${ }^{*}$ At time of vulval diagnosis.

Conclusion There were no cases of invasive vulval carcinoma. HSV-2 may cause atypical disease even in the context of near-complete immune reconstitution on cART. Most women with vulval disease were already under HIV care, on CART and had a CD4 cell count above 200 cells/ $\mu 1$

\section{P181 MANAGEMENT OF RECURRENT VULVOVAGINAL CANDIDIASIS AND RECURRENT BACTERIAL VAGINOSIS IN NORTH EAST LONDON NETWORK FOR SEXUAL HEALTH AND HIV (NELNET)}

doi:10.1136/sextrans-2012-050601c.181

S Navsaria, S M Lowe, ${ }^{*}$ C S Estcourt. Barts and the London NHS Trust, London, UK

Background Recurrent Vulvovaginal Candidiasis (VVC) and Bacterial Vaginosis (BV) are common, associated with significant morbidity, often impact on psychological well-being and can be 
relatively costly to manage. BASHH guidelines acknowledge that the evidence base for recommendations is poor. We aimed to describe the management regimes of GUM Consultants who routinely manage these conditions within our large network prior to introducing sector-wide guidelines.

Method We emailed appropriate GUM consultants from the six network centres requesting their standard management regimes for both conditions. We collated the responses and used BASHH Guidelines as a standard for comparison

Results All 14 consultants responded. Treatment regimes for VVC were broadly similar but only three consultants prescribed according to BASHH Guidelines. 13 consultants prescribed induction regimes. All consultants used oral fluconazole, doses included 50, 100 and $150 \mathrm{mg}$. Duration of induction regimes ranged from 3 daily doses, alternate day doses, $72 \mathrm{~h}$ doses to daily dose for 14 days. Ten consultants prescribed maintenance therapy for 6 months, 4 stopped after 3 months. 11 consultants prescribed $150 \mathrm{mg}$ weekly for at least 3 months. For recurrent BV there was considerable variation and no one followed BASHH guidelines. Regimes included oral metronidazole (2 g, $400 \mathrm{mg}$ ), metronidazole gel or clindamycin pessaries. Induction ranged from 5 to 14 days, maintenance from 3 to 6 months. All consultants prescribed menstrual regimes if appropriate. Three consultants also prescribed Balance Activ or equivalent.

Conclusion Management of recurrent BV and VVC varied greatly across the network. Management of recurrent VVC was more closely associated with BASHH guidelines than management of recurrent BV. Management regimes are often based on clinicians' own experience. New network guidance has now been established providing a local standard for future case record audit.

\section{P182 IS IT USEFUL TO PERFORM A FULL PHYSICAL EXAMINATION IN ASYMPTOMATIC PATIENTS WITH LATE SYPHILIS?}

doi:10.1136/sextrans-2012-050601c.182

\section{R Dabis, ${ }^{*}$ K Radcliffe. University of Birmingham, Birmingham, UK}

Background In late and congenital syphilis a thorough physical examination should be undertaken for signs of syphilis as per British Association for Sexual Health and HIV guidelines. This should include examination of skin and mucosal surfaces, lymph nodes, the cardiovascular and neurological systems.

Aims To audit all cases of late syphilis at our centre to see if a full cardiovascular and neurological examination was documented and also to see if a full examination contributed to the management of asymptomatic patients.

Methods A total of 648 notes were identified as late syphilis from KC60 codes from our local database. Records were from the period 1994 to 2010.The following information was extracted from the clinical records: age, ethnicity, gender, sexuality, symptomatic/ asymptomatic, cardiovascular and neurological examination findings and further action taken where applicable. 148 notes were unavailable. 20 notes were excluded. Therefore 480 notes in total were audited.

Results Of the 480 patients, $262(55 \%)$ were of Black Caribbean ethnicity, 75 (16\%) White British, 68 (14\%) Black African and 75 $(16 \%)$ others. $240(50 \%)$ were heterosexual males, 206 (43\%) heterosexual females, 31 (6\%) men who have sex with men. Information on sexual orientation was not available in 3 (1\%). 295 patients were asymptomatic of which 288 (98\%) had normal physical examinations. Seven asymptomatic patients had positive clinical findings but these did not lead to a diagnosis of cardiovascular or neurological syphilis. In 99 cases a full examination was not documented and in 21 cases patients declined or defaulted further follow-up. There were 65 symptomatic patients all had abnormal physical findings.

Conclusion In view of the absence of significant clinical examination findings in asymptomatic patients with late syphilis we believe that a physical examination is not a necessary element in the management of such cases and should be omitted.

\section{P183 HOW LIKELY IS ENVIRONMENTAL CONTAMINATION OF CHLAMYDIA TRACHOMATIS DNA TO LEAD TO FALSE POSITIVE RESULTS IN PATIENTS ATTENDING OUR CLINIC?}

doi:10.1136/sextrans-2012-050601c.183

${ }^{1} \mathrm{~S} Y$ Chan, ${ }^{* 1} \mathrm{R}$ King, ${ }^{2} \mathrm{G}$ Borgulya, ${ }^{1} \mathrm{M}$ Pakianathan, ${ }^{2} \mathrm{~S}$ T Sadiq, ${ }^{1} \mathrm{P}$ Hay, ${ }^{1} \mathrm{~T}$ Planche. ${ }^{1} \mathrm{St}$ George's Healthcare NHS Trust, London, UK; ${ }^{2}$ St George's University of London, London, UK

Background Environmental contamination with DNA from Chlamydia trachomatis (CT) has been reported from GUM clinics, suggesting the possibility of cross contamination of specimens during sample processing or the environment. If it does occur, contamination is likely dependent to some degree on how busy patient throughput is in a clinic. Our GUM clinic sees over 29000 patients a year.

Aims To investigate whether diagnostic samples could become contaminated from the environment in our clinic.

Methods We investigated the potential for contamination in two ways. (1) A dummy run of 60 sterile water samples, as surrogates of urine and 10 sterile swabs during routine clinic times. (2) A patient throughput study using logistic regression analysis to see if patients positive for CT were associated with attendance numbers. We hypothesise that possible contamination increases after each infected patient and drops off to zero over the weekend. Our clinic is open from Monday to Friday and cleaned daily. Toilets are not cleaned between patients. Results were analysed for walk in clinics.

Results None of the dummy urine or swabs tested positive for CT over 6 months. In a year, 24115 patients attended the walk in clinics with $2860(11.9 \%)$ testing positive for CT. A logistic regression analysis was done on CT positivity on Mondays compared to Tuesdays to Fridays. This was adjusted for age, gender, sexuality and type of clinic. Rates of CT were $5 \%$ higher on Tuesdays through Fridays than on Mondays but the difference was not significant (95\% CI 0.95 to 1.16 ).

Conclusion There was no evidence of dummy sample contamination during our study period. We found weak association between CT positivity and clinic attendance although it was not significant at the $5 \%$ level. Further studies with a larger sample size and analysis on within day trends could explore this in depth. Environmental CT is unlikely to lead to false positive results in our clinic.

\section{P184 PEYRONIE'S DISEASE PRESENTING TO A SEXUAL HEALTH CLINIC}

doi:10.1136/sextrans-2012-050601c.184

E M Draeger, ${ }^{*}$ S D Dharmaratne, B T Goh. Barts and the London NHS Trust, London, UK

Background Peyronie's disease (PD) is an acquired inflammatory condition of the corpus cavernosum of unknown aetiology. This can lead to formation of a plaque within the tunica albuginea of the penis leading to curvature and pain of the erect penis and erectile dysfunction. Medical treatment options are with colchicine or pentoxifyline. 